\title{
HUBUNGAN ANTARA PEMBERIAN HUKUMAN DENGAN PEMBENTUKAN KARAKTER SISWA
}

\author{
Taufik \\ Dosen STKIP Muhammadiyah Barru \\ Email: bumangnafiz@yahoo.com
}

\begin{abstract}
ABSTRAK
Penelitian ini merupakan penelitian kualitatif yang bertujuan untuk mengetahui hubungan antara pemberian hukuman dengan pembentukan karakter. Penelitian ini dilaksankan di sekolah SMK Negeri 2 Barru yang berada di desa CoppengCoppeng Kecamatan Tanete Rilau Kabupaten Barru. Adapun jenis penelitian yang digunakan adalah penelitian korelasional. Penentuan sampel dalam penelitian ini diambil secara proportional random sampling. Teknik pengumpulan data menggunakan pengumpulan triangulasi data yaitu Observasi, angket, dan dokumentasi. Hasil penelitian menunjukkan bahwa nilai $\mathrm{r}$ atau korelasi antara variabel adalah 0,6 yang berarti hubungannya cukup kuat/tinggi. Sementara pada uji hipotesis ternyata $t$ hitung lebih besar dari t tabel, atau 6,22>1,995 maka dapat disimpulkan bahwa Ho di tolak artinya terdapathubungan antara pemberian hukuman dengan pembentukan karakter siswa di SMK Negeri 2 Barru.
\end{abstract}

Kata Kunci: Hukuman, Karakter, Siswa.

\section{RELATIONSHIP BETWEEN THE GRANTING OF PUNISHMENT AND THE ESTABLISHMENT OF STUDENT CHARACTER}

\begin{abstract}
This research is a qualitative research which aims to determine the relationship between punishment and character building. This research was carried out at the SMK Negeri 2 Barru in Coppeng-Coppeng Village, Tanete Rilau District, Barru Regency. The type of research used is correlational research. The samples in this study were taken by proportional random sampling. Data collection techniques using data triangulation collection namely observation, questionnaires, and documentation. The results showed that the value of $r$ or the correlation between variables was 0.6, which means that the relationship is quite strong / high. While in the hypothesis test, it turns out that $t$ count is greater than t table, or 6.22> 1.995, it can be concluded that Ho is rejected, meaning that there is a relationship between punishment and character building of students at SMK Negeri 2 Barru.
\end{abstract}

Keywords: Punishment, Character, Students.

\section{PENDAHULUAN}

Dunia pendidikan kita juga mengenal jenis hukuman pada siswa, hukuman pada siswa tentu berbeda dengan penerapan hukum adat, atau hukum negara, 
pemberian hukuman pada siswa dimaksudkan untuk memperbaiki siswa yang berbuat salah dengan harapan agar selanjutnya tidak melakukan kesalahan lagi atau insaf atas kesalahannya, insaf yang timbul dari kesadaran hatinya, sehingga tidak ingin mengulangi lagi. Penyadaran atas hal-hal yang menyebabkan masalah ini penting dengan maksud agar dengan usaha sendiri (Self direction), mereka dapat mengatasi dan memperbaikinya.

Dengan uraian diatas berarti hukuman tersebut dapat dipertanggung jawabkan secara pedagogis apabila hukuman tersebut dapat menginsafkan siswa atas perbuatannya yang salah.Siswa mempunyai pengertian tentang akibat perbuatan yang baik dan buruk.Karena hal-hal yang demikianlah hukuman yang bersifat memperbaiki sering disebut hukuman pedagogis. Jadi hukuman dapat diterapkan dalam pendidikan terutama hukuman yang bersifat pedagogis, menghukum bila perlu jangan terus-menerus dan hindarilah hukuman jasmani. Karena dengan memberikan hukuman fisik atau sering terkena hukuman, dapat saja berdampak pada psikologi si anak, dan bisa jadi dengan pemberian hukuman yang tidak pedagogis, akan memberikan dampak permanen pada mental atau psikologi siswa.

Setelah melihat adanya dampak psikologipada hukuman terhadap siswa, sudah saatnya para pendidik kembali mempertanyakan esensi dari hukuman. Pertanyaan utamanya tentu adalah kenapa hukuman harus terjadi? Sebagai seorang guru, kebanyakan hukuman itu terjadi karena peraturan yang tidak jelas. Setelah itu, hukuman sangat erat kaitannya dengan mental, moral hingga masalah harga diri seorang guru. Inti dari semua hukuman itu hanyalah berpusat pada dua kata, pendisiplinan dan kepribadian.

Hukuman sebenarnya dapat berpengaruh terhadap karakter siswa, siswa yang tidak terbiasa dihukum akan merasakan makna dari hukuman yang diterimanya, maka perubahan dapat langsung terlihat. Akan tetapi bagi siswa yang memang sering kali kena hukuman maka yang harus dipertimbangkan adalah efek jera dari hukuman yang diberikan sehingga akan perubahan karakter pada dirinya. Menurut Amin Danien Indrakusuma (2003:14) bahwa hukuman adalah tindakan yang dijatuhkan kepada anak secara sadar dan sengaja sehingga 
menimbulkan nestapa, dan dengan adanya nestapa itu anak akan menjadi sadar akan perbuatannya dan berjanji di dalam hatinya untuk tidak mengulanginya. Menurut Hendrijanto (2011:1) bahwa: Memberikan hukuman kepada anak didik, seorang pendidik harus memperhatikan tiga macam aturan: 1). Hukuman harus selaras dengan kesalahan, 2). Hukuman harus adil, 3). Hukuman harus lekas dijatuhkan.

K. Singh dan Mr. A.R. Agwan dalam Encyclopaedia of the Holy Qur'ân, (2000:175) bahwa "Menurut bahasa, karakter adalah tabiat atau kebiasaan." Sedangkan menurut ahli psikologi, karakter adalah sebuah sistem keyakinan dan kebiasaan yang mengarahkan tindakan seorang individu. Karena itu, jika pengetahuan mengenai karakter seseorang itu dapat diketahui, maka dapat diketahui pula bagaimana individu tersebut akan bersikap untuk kondisi-kondisi tertentu.

Sedangkan Menurut Suyanto (2009:55) mendefinisikan bahwa Karakter sebagai cara berpikir dan berperilaku yang menjadi ciri khas tiap individu untuk hidup dan bekerja sama, baik dalam lingkup keluarga, masyarakat, bangsa, maupun Negara. Thomas Lickona (2012:79) menyatakan bahwa pendidikan karakter adalah suatu usaha yang disengaja untuk membantu seseorang sehingga ia dapat memahami, memperhatikan, dan melakukan nilai-nilai etika yang inti. Lebih lanjut di kemukankan oleh Dali Gulo dalam buku Strategi Belajar Mengajar (2010:29) bahwa Karakter adalah kepribadian ditinjau dari titik tolak etis atau moral, misalnya kejujuran seseorang, dan biasanya berkaitan dengan sifat-sifat yang relatif tetap.

Pendidikan karakter adalah suatu sistem penanaman nilai-nilai karakter kepada warga sekolah yang meliputi komponen pengetahuan, kesadaran atau kemauan, dan tindakan untuk melaksanakan nilai-nilai tersebut. Pendidikan karakter dapat dimaknai sebagai "The deliberate use of all dimensions of school life to foster optimal character development". Dalam pendidikan karakter di sekolah, semua komponen (pemangku pendidikan) harus dilibatkan, termasuk komponen-komponen pendidikan itu sendiri, yaitu isi kurikulum, proses pembelajaran dan penilaian, penanganan atau pengelolaan mata pelajaran, 
pengelolaan sekolah, pelaksanaan aktivitas atau kegiatan ko-kurikuler, pemberdayaan sarana prasarana, pembiayaan, dan ethos kerja seluruh warga sekolah/lingkungan. Di samping itu, pendidikan karakter dimaknai sebagai suatu perilaku warga sekolah yang dalam menyelenggarakan pendidikan harus berkarakter

Dalam pengembangan karakter peserta didik di sekolah, guru memiliki posisi yang strategis sebagai pelaku utama. Guru merupakan sosok yang bisa digugu dan ditiru atau menjadi idola bagi peserta didik. Guru bisa menjadi sumber inpirasi dan motivasi peserta didiknya. Sikap dan prilaku seorang guru sangat membekas dalam diri siswa, sehingga ucapan, karakter dan kepribadian guru menjadi cermin siswa. Dengan demikian guru memiliki tanggung jawab besar dalam menghasilkan generasi yang berkarakter, berbudaya, dan bermoral. Tugastugas manusiawi itu merupakan transpormasi, identifikasi, dan pengertian tentang diri sendiri, yang harus dilaksanakan secara bersama-sama dalam kesatuan yang organis, harmonis, dan dinamis.

Pengembangan atau pembentukan karakter diyakini perlu dan penting untuk dilakukan oleh sekolah dan stakeholders-nya untuk menjadi pijakan dalam penyelenggaraan pendidikan karakter di sekolah. Tujuan pendidikan karakter pada dasarnya adalah mendorong lahirnya anak-anak yang baik (insan kamil). Tumbuh dan berkembangnya karakter yang baik akan mendorong peserta didik tumbuh dengan kapasitas dan komitmennya untuk melakukan berbagai hal yang terbaik dan melakukan segalanya dengan benar dan memiliki tujuan hidup.

Menurut Maksudi (2013:23) bahwa Karakter akan terbentuk sebagai hasil pemahaman hubungan yang pasti dialami setiap manusia (trianglerelationship), yaitu hubungan dengan diri sendiri (intrapersonal), dengan lingkungan (hubungan sosial dan alam sekitar), dan hubungan dengan Tuhan YME (spiritual). Setiap hasil hubungan tersebut akan memberikan pemaknaan/pemahaman yang pada akhirnya menjadi nilai dan keyakinan anak. Selanjutnya menurut Sunarto (2008:45) bahwa dalam membangun karakter seorang siswa, pihak sekolah perlu memperhatikan aturan dan tata tertib yang berlaku disekolah. Di era globalisasi 
ini, banyak sekolah sudah jarang sekali menerapkan nilai-nilai luhur Pancasila sehingga hubungan antara guru dan siswa tidak begitu akrab.

\section{METODE PENELITIAN}

Penelitian ini menggunakan pendekatan kuantitatif. Penelitian kuantitatif menurut Sugiyono (2017: 13) bahwa penelitian kuantitatif disebut juga metode positivisme karena menggunakan data penelitian berupa angka-angka dan analisis secara statistik. Jenis penelitian menggunakan jenis penelitian korelasional. Menurut Anas Sudijono (2010:179) bahwa dalam statistik korelasi diberi pengertian sebagai hubungan antara dua variabel atau lebih." Data variabelvariabel akan dinominasikan dalam bentuk angka-angka kuantitatif yang selanjutnya akan diolah untuk melihat hubungan yang terjadi pada kedua variabel, besar dan kecil hubungannya dengan menggunakan kaidah statistika.

Populasi dalam penelitian ini adalah keseluruhan siswa SMK Negeri 2 Barru pada kelas X, XI, danXII.

Tabel 1. Data Populasi SMK Negeri 2 Barru

\begin{tabular}{|c|c|c|c|}
\hline \multirow{2}{*}{ Kelas } & \multicolumn{2}{|c|}{ Jenis Kelamin } & \multirow{2}{*}{ Jumlah } \\
\cline { 2 - 3 } & Laki-laki & Perempuan & \\
\hline X.TKJ-1 & 23 & 21 & 44 \\
\hline X.TKJ -2 & 11 & 31 & 42 \\
\hline X.TKR-1 & 38 & 1 & 39 \\
\hline X.TKR-2 & 40 & 0 & 40 \\
\hline X.TSM & 29 & 1 & 30 \\
\hline X.MM & 16 & 28 & 44 \\
\hline X.NKPI-1 & 26 & 0 & 26 \\
\hline X.NKPI-2 & 25 & 0 & 25 \\
\hline XI.TKJ-1 & 8 & 19 & 27 \\
\hline XI.TKJ-2 & 14 & 9 & 23 \\
\hline XI.TKJ-3 & 13 & 13 & 26 \\
\hline XI.TSM & 28 & 0 & 28 \\
\hline XI. MM & 19 & 16 & 35 \\
\hline XI. NKP-1 & 39 & 0 & 39 \\
\hline
\end{tabular}




\begin{tabular}{|c|c|c|c|}
\hline \multirow{2}{*}{ Kelas } & \multicolumn{2}{|c|}{ Jenis Kelamin } & \multirow{2}{*}{ Jumlah } \\
\cline { 2 - 3 } & Laki-laki & Perempuan & \\
\hline XI. TKR & 38 & 0 & 38 \\
\hline XII.MO-1 & 38 & 0 & 38 \\
\hline XII.MO-2 & 38 & 0 & 38 \\
\hline XII.TKJ-1 & 20 & 14 & 34 \\
\hline XII.TKJ-2 & 18 & 14 & 32 \\
\hline XII. MM & 8 & 25 & 33 \\
\hline XII. NKPI & 30 & 0 & 30 \\
\hline JUMLAH & 519 & 192 & 711 \\
\hline
\end{tabular}

Sumber data: TU SMK Negeri 2 Barru

Jumlah sampel pada tiap kelas dan jenis kelamin sebagai berikut:

Tabel 2. Data Sampel SMK Negeri 2 Barru

\begin{tabular}{|c|c|c|c|}
\hline \multirow{2}{*}{ Kelas } & \multicolumn{2}{|c|}{ Jenis Kelamin } & \multirow{2}{*}{ Jumlah } \\
\cline { 2 - 4 } & Laki-laki & Perempuan & \\
\hline X.TKJ-1 & 2 & 2 & 4 \\
\hline X.TKJ -2 & 1 & 3 & 4 \\
\hline X.TKR-1 & 4 & 0 & 4 \\
\hline X.TKR-2 & 4 & 0 & 4 \\
\hline X.TSM & 3 & 0 & 3 \\
\hline X.MM & 2 & 2 & 4 \\
\hline X.NKPI-1 & 3 & 0 & 3 \\
\hline X.NKPI-2 & 2 & 0 & 2 \\
\hline XI.TKJ-1 & 1 & 2 & 3 \\
\hline XI.TKJ-2 & 1 & 1 & 2 \\
\hline XI.TKJ-3 & 2 & 1 & 3 \\
\hline XI.TSM & 3 & 0 & 3 \\
\hline XI. MM & 1 & 2 & 3 \\
\hline XI. NKP-1 & 4 & 0 & 4 \\
\hline XI. TKR & 4 & 0 & 4 \\
\hline XII.MO-1 & 4 & 0 & 4 \\
\hline XII.MO-2 & 4 & 0 & 4 \\
\hline XII.TKJ-1 & 2 & 2 & 4 \\
\hline XII.TKJ-2 & 2 & 1 & 3 \\
\hline XII. MM & 1 & 2 & 3 \\
\hline
\end{tabular}




\begin{tabular}{|c|c|c|c|}
\hline \multirow{2}{*}{ Kelas } & \multicolumn{2}{|c|}{ Jenis Kelamin } & \multirow{2}{*}{ Jumlah } \\
\cline { 2 - 4 } & Laki-laki & Perempuan & \\
\hline XII. NKPI & 3 & 0 & 3 \\
\hline JUMLAH & 52 & 19 & 71 \\
\hline
\end{tabular}

Sumber Data: Hasil pengolahan data populasi

\section{HASIL PENELITIAN DAN PEMBAHASAN}

Setelah ditentukan variabel x yaitu konsep diri, dan variabel y perubahan perilaku siswa, maka angket di sebar dengan indikator tertentu. Adapun angket tersebut akan dihitung berdasarkan pertanyaan negatif dan positif. Bila bernilai negatif maka dimulai dari nilai $\mathrm{SS}=1, \mathrm{~S}=2, \mathrm{KS}=3, \mathrm{TS}=4, \mathrm{STS}=5$. Untuk nilai positif $\mathrm{SS}=5, \mathrm{~S}=4, \mathrm{KS}=3, \mathrm{TS}=2, \mathrm{STS}=1$. Setelah dilakukan perhitungan, maka dapat diketahui jumlah angketnya sebagaimana terlampir.

Pada lampirandapat diketahui nilai statistik x dan y sebagai berikut:

$$
\begin{aligned}
\mathrm{n} & =71 \\
\sum \mathrm{x} & =2195 \\
\sum \mathrm{y} & =3640 \\
\sum \mathrm{X}^{2} & =68909 \\
\sum \mathrm{Y}^{2} & =189068 \\
\sum \mathrm{xy} & =113540
\end{aligned}
$$

Rumus product moment

$$
\begin{gathered}
\frac{n\left(\sum X Y\right)-\left(\sum X\right)\left(\sum Y\right)}{\sqrt{\left(n \sum X^{2}-\left(\sum X\right)^{2}\right)\left(n \sum Y^{2}-\left(\sum Y\right)^{2}\right)}} \quad \mathrm{r}_{X Y}= \\
\mathrm{r}_{X Y}= \\
= \\
= \\
= \\
=\mathbf{0 , 6}
\end{gathered}
$$


Untuk pengujian hipotesis, maka akan dilakukan dengan mencari besarnya signifikansi antara $\mathrm{t}$ tabel dan thitung. Adapun bunyi hipotesis dari penelitian ini adalah "Ada hubungan antara pemberian hukuman dengan pembentukan karakter siswa di SMK Negeri 2 Barru.

Dengan demikian, hipotesis tersebut dapat dibuat dalam bentuk kalimat sebagai berikut:

$$
\begin{aligned}
\mathrm{Ha}= & \text { Terdapathubungan antara pemberian hukuman dengan pembentukan } \\
& \text { karakter siswa di SMK Negeri } 2 \text { Barru } \\
\text { Ho = } & \text { Tidak terdapathubungan antara pemberian hukuman dengan } \\
& \text { pembentukan karakter siswa di SMK Negeri } 2 \text { Barru. }
\end{aligned}
$$

Langkahnya adalah menemukan $\mathrm{t}$ hitung dan $\mathrm{t}$ tabel

diketahui:

$$
\begin{aligned}
& \mathrm{r}=0,6 \\
& \mathrm{n}=71 \\
& \mathrm{t}_{\text {hitung }}= \\
& \mathrm{t}_{\text {hitung }}= \\
& \mathrm{t}_{\text {hitung }}= \\
& \mathrm{t}_{\text {hitung }}= \\
& \mathrm{t}_{\text {hitung }}=6,22
\end{aligned}
$$

Kaidah pengujian hipotesis adalah :

Jika thitung ttabel maka tolak Ho artinya signifikan, dan

Jika thitung $\leq$ ttabel maka terima Ho artinya tidak signifikan

Berdasarkan perhitungan di atas dengan $\alpha=0,05$ dan $\mathrm{n}=71$ maka $\mathrm{dk}=\mathrm{n}-2=71-2$ $=69$, sehingga diperoleh ttabel $=1,995$ (berdasarkan distribusi nilai $\mathrm{t}$ dapat dilihat pada lampiran) Ternyata thitung lebih besar dari ttabel, atau 6,22>1,995 maka dapat disimpulkan bahwa Ho di tolak artinya terdapathubungan antara pemberian hukuman dengan pembentukan karakter siswa di SMK Negeri 2 Barru.

Hukuman dilakukan bila hukuman itu dapat dipertanggungjawabkan secara pedagogis, artinya dilakukan dengan mempertimbangkan unsur pendidikan 
di dalamnya.Jadi, menghukum bila perlu jangan terus-menerus dan hindarilah hukuman jasmani. Karena dengan memberikan hukuman fisik atau sering terkena hukuman, dapat saja berdampak pada psikologi si anak, dan bisa jadi dengan pemberian hukuman yang tidak pedagogis, akan memberikan dampak permanen pada mental atau psikologi siswa.

Setelah melihat adanya dampak psikologipada hukuman terhadap siswa, sudah saatnya para pendidik kembali mempertanyakan esensi dari hukuman. Pertanyaan utamanya tentu adalah kenapa hukuman harus terjadi? Sebagai seorang guru, kebanyakan hukuman itu terjadi karena peraturan yang tidak jelas. Setelah itu, hukuman sangat erat kaitannya dengan mental, moral hingga masalah harga diri seorang guru. Inti dari semua hukuman itu hanyalah berpusat pada dua kata, pendisiplinan dan kepribadian. Menjadi ketimpangan adalah segala sesuatunya hanya bertitik berat pada siswa, bukan guru. Karena itu, sebelum hukuman, apalagi hukuman fisik terjadi, hal yang pertama yang perlu dilakukan adalah peninjauan setiap peraturan yang ada di sekolah bahkan departemen pendidikan sendiri.

Setiap aturan itu seharusnya punya penjelasan logis dan hubungan sebab akibat. Peraturan seharusnya mendidik siswa untuk disiplin secara mandiri bukan menakut-nakuti apalagi sampai membuat siswa trauma. Hukuman sebenarnya dapat berpengaruh terhadap karakter siswa, siswa yang tidak terbiasa dihukum akan merasakan makna dari hukuman yang diterimanya, maka perubahan dapat langsung terlihat. Akan tetapi bagi siswa yang memang sering kali kena hukuman maka yang harus dipertimbangkan adalah efek jera dari hukuman yang diberikan sehingga akan perubahan karakter pada dirinya.

Hasil penelitian menunjukkan bahwa nilai $\mathrm{r}$ atau korelasi antara variabel adalah 0,6 yang berarti hubungannya cukup kuat/tinggi. Sementara pada uji hipotesis ternyata thitung lebih besar dari ttabel, atau 6,22>1,995 maka dapat disimpulkan bahwa Ho di tolak artinya terdapathubungan antara pemberian hukuman dengan pembentukan karakter siswa di SMK Negeri 2 Barru. 


\section{KESIMPULAN}

Berdasarkan hasil penelitian maka dapat disimpulkan bahwa terdapathubungan antara pemberian hukuman dengan pembentukan karakter siswa di SMK Negeri 2 Barru. Hal ini dapat dilihat dari hasil korelasi atau nilai r sebesar 0,6 yang berarti bahwa hubungan antara kedua variabel cukup tinggi. Juga pada uji hipotesis dengan uji t, maka diketahui bahwa ternyata thitung lebih besar dari ttabel, atau 6,22>1,995 yang berarti hipotesis yang menyatakan ada pengaruh antara kedua variabel diterima.

\section{SARAN}

1. Bagi orang tua

Agar senantiasa memberikan perhatian terhadap anaknya termasuk pada pendidikannya agar selalu rajin kesekolah supaya pemberian hukuman tidak sering terjadi.

2. Bagi penulis

Semoga hasil penelitian ini dapat dijadikan sebagai sumber informasi dan materi yang dapat membantu wawasan serta ilmu pengetahuan dengan masalah yang nantinya menjadi acuan bagi peneliti selanjutnya.

3. Bagi penulis selanjutnya

Saya sarankan bagi penelti selanjutnya agar melaksanakan penelitian lebih mendalam, dalam arti bukan hanya melihat gambaran dari responden akan tetapi harus menelusuri secara mendalam permasalahan yang di alami responden.

\section{DAFTAR PUSTAKA}

Amin Danien Indrakusuma. 2003. Pengantar Ilmu Pengetahuan. Malang : UMM Pres. Malang

Anas Sudijono. 2010. Pengantar Statistik Pendidikan. Jakarta : Raja Grafindo Persada.

Dali Gulo. 2010. Strategi Belajar Mengajar. Jakarta : Grasindo. 
JUANG: JurnalWahanaKonseling (Vol. 4, No. 1, Maret 2021)

Hendrijanto, Agoes. 2011. Teori belajar dan pembelajaran. Bandung : Buku Ilmu.

K. Singh dan Mr. A.R. Agwan, 2000. Encyclopaedia of the Holy Qur'ân. New Delhi : Balaji Offset.

Maksudin, 2013. Pendidikan Karakter Non-Dikotomi. Yogyakarta : Pustaka Pelajar.

Sugiyono. 2017. Metode Penelitian Kuantitatif dan Kualitatif. Bandung : Alfabeta.

Sunarto. 2008. Perkembangan Peserta Didik. Jakarta : Rineka Cipta.

Suyanto. 2009. Menjelajah Pembelajaran Inovatif. Jakarta : Gramedia.

Thomas Lickona. 2012. Mendidik Untuk Membentuk Karakter. Jakarta : Bumi Aksara. 